\title{
Type IV secretion of Helicobacter pylori CagA into oral epithelial cells is prevented by the absence of CEACAM receptor expression
}

\author{
Nicole Tegtmeyer ${ }^{1 *} \mathbb{D}$, Tabita Denisia Ghete ${ }^{1}$, Verena Schmitt ${ }^{2}$, , Torsten Remmerbach ${ }^{3}$, \\ Maria Celeste C. Cortes ${ }^{4}$, Edgardo M. Bondoc ${ }^{5}$, Hans-Ludwig Graf ${ }^{6}$, Bernhard B. Singer ${ }^{2}$, Christian Hirsch ${ }^{7}$ \\ and Steffen Backert ${ }^{1}$
}

\begin{abstract}
Background: Helicobacter pylori typically colonizes the human stomach, but it can occasionally be detected in the oral cavity of infected persons. Clinical outcome as a result of gastric colonization depends on presence of the pathogenicity island cagPAl that encodes a type-IV secretion system (T4SS) for translocation of the effector protein CagA and ADP-heptose. Upon injection into target cells, CagA is phosphorylated, which can be demonstrated by in vitro infection of the gastric epithelial cell line AGS, resulting in cell elongation. Here we investigated whether H. pylori can exert these responses during interaction with cells from the oral epithelium. To this purpose, three oral epithelial cell lines, HN, CAL-27 and BHY, were infected with various virulent wild-type H. pylori strains, and CagA delivery and ADPheptose-mediated pro-inflammatory responses were monitored.

Results: All three oral cell lines were resistant to elongation upon infection, despite similar bacterial binding capabilities. Moreover, T4SS-dependent CagA injection was absent. Resistance to CagA delivery was shown to be due to absence of CEACAM expression in these cell lines, while these surface molecules have recently been recognized as $H$. pylori T4SS receptors. Lack of CEACAM expression in HN, CAL-27 and BHY cells was overcome by genetic introduction of either CEACAM1, CEACAM5, or CEACAM6, which in each of the cell lines was proven sufficient to facilitate CagA delivery and phosphorylation upon H. pylori infection to levels similar to those observed with the gastric AGS cells. Pro-inflammatory responses, as measured by interleukin-8 ELISA, were induced to high levels in each cell line and CEACAM-independent.
\end{abstract}

Conclusions: These results show that lack of CEACAM receptors on the surface of the oral epithelial cells was responsible for resistance to $\mathrm{H}$. pylori CagA-dependent pathogenic activities, and confirms the important role for the T4SS-dependent interaction of these receptors with H. pylori in the gastric epithelium.

Keywords: AGS, HN, CAL-27, BHY, CEACAM, CagA, Signaling, Type IV secretion, T4SS, Tyrosine kinases

\section{Background}

Helicobacter pylori colonizes the gastric mucosa and represents a main risk factor for gastric cancer.

*Correspondence: Nicole.Tegtmeyer@fau.de

1 Department of Biology, Division of Microbiology, Friedrich Alexander University Erlangen, Staudtstrasse 5, 91058 Erlangen, Germany

Full list of author information is available at the end of the article
Approximately half of the global population is infected, and although most infections remain asymptomatic, in approximately $10-15 \%$ of infected individuals peptic ulceration occurs, and $1-2 \%$ may eventually develop gastric cancer $[1,2]$. No host other than humans is known to be naturally infected by $H$. pylori, and survival outside the human body is limited. Most H. pylori infections initiate during early childhood and strain similarity

c) The Author(s) 2020. This article is licensed under a Creative Commons Attribution 4.0 International License, which permits use, sharing, adaptation, distribution and reproduction in any medium or format, as long as you give appropriate credit to the original author(s) and the source, provide a link to the Creative Commons licence, and indicate if changes were made. The images or other third party material in this article are included in the article's Creative Commons licence, unless indicated otherwise in a credit line to the material. If material is not included in the article's Creative Commons licence and your intended use is not permitted by statutory regulation or exceeds the permitted use, you will need to obtain permission directly from the copyright holder. To view a copy of this licence, visit http://creativeco mmons.org/licenses/by/4.0/. The Creative Commons Public Domain Dedication waiver (http://creativecommons.org/publicdomain/ zero/1.0/) applies to the data made available in this article, unless otherwise stated in a credit line to the data. 
within families suggests a parental (maternal) origin, but whether transmission occurs mainly via the oral-oral or (also) via the fecal-oral route remains subject of much debate [3-5]. Live H. pylori can sometimes be detected in diarrhoeic stools of infected individuals [4]. On occasion, presence of live H. pylori or H. pylori DNA has also been demonstrated in the oral cavity, mostly from specimens of dental plaque, oral mucosa, saliva or within the infected root canals of non-vital teeth $[4,6,7]$. Temporary presence of $H$. pylori in the mouth may be the result of reflux $[6,8,9]$ and a meta-analysis identified an intimate association of $H$. pylori presence in the oral environment and in the stomach [10]. H. pylori is more difficult to eradicate from the oral cavity than from the stomach, so that oral populations may provide a source of infection to other individuals upon contact.

Colonization in the stomach depends on a number of bacterial factors, while the clinical outcome relates to presence of a chromosomally encoded pathogenicity island (PAI) carrying virulence determinants $[11,12]$. This so-called cagPAI is only present in highly virulent strains and encodes a type-IV secretion system (T4SS) that translocates the effector protein CagA into gastric epithelial cells [13-15]. Subsequently, CagA hijacks cellular signal transduction events and causes gastric AGS cells to migrate and elongate [16]. CagA injection into host cells depends on at least 15 cagPAI-encoded T4SS proteins $[17,18]$. The $C$-terminal end of CagA contains four so-called EPIYA motifs (A, B, C or D) that, once the protein is intracellularly delivered, are tyrosine-phosphorylated by host $\mathrm{Abl}$ and Src kinase family members [19]. The occurrence of phosphorylated CagA ( $\mathrm{CagA}^{\mathrm{PY}}$ ) is a hallmark of CagA function and an indication for its successful delivery into the host cells. $H$. pylori further expresses various adhesins on its outer membrane including BabA/B, SabA, OipA, and AlpA/B [20, 21]. Another identified adhesin, HopQ, was shown recently to bind to surface-exposed CEACAM receptors (short for carcinoembryonic antigen-related cell adhesion molecule) of the host cells. In particular, HopQ specifically interacts with the human members CEACAM1, CEACAM3, CEACAM5 and CEACAM6, and this interaction permits bacterial adhesion and is essential for delivery of CagA into a given cell [22-25]. The binding between HopQ and CEACAM can trigger CEACAM-dependent host cell signal transduction, which is a requirement for $H$. pylori colonization, T4SS functions and development of gastric pathology. However, the involved molecular mechanisms are still not fully clear.

Most of the known gastric epithelial cell lines can express CEACAM receptors and permit CagA injection [22-26]. However, whether CEACAM receptors play a role in bacterial colonization of the oral cavity has not been studied yet. Here, we investigated whether epithelial cells from the oral cavity express CEACAMs and whether they can permit CagA delivery by the T4SS of H. pylori. Three oral epithelial cell lines were compared, which we found were all lacking CEACAM expression and were discovered to be resistant to CagA injection. This indicates that the gastric and oral environments display different susceptibilities for T4SS effectors.

\section{Results}

Oral HN, CAL-27 and BHY cell lines reveal absence of cell elongation following in vitro infection with $H$. pylori strains Three different cell lines originating from oral epithelial cells, HN, CAL-27 and BHY, were infected with $H$. pylori and cell morphology was compared to an infected gastric epithelial AGS cell line. Eight $H$. pylori wild-type isolates that had been isolated from various parts of the world were included. A T4SS-deficient cagY knockout mutant $(\Delta \operatorname{cag} Y)$ that can no longer express CagY, which is part of the T4SS outer membrane core complex [15], was included as control. Following infection with $H$. pylori for $6 \mathrm{~h}$ at a multiplicity of infection (MOI) of 100, the cells were investigated by phase contrast microscopy to reveal cell elongation that is the typical outcome in infected gastric AGS cells as a result of CagA's pathogenic activities. Figure $1 \mathrm{a}-\mathrm{d}$ shows that cell elongation was absent in HN, CAL-27 and BHY cells infected with H. pylori strain Gam94-24 as an example. Cell elongation observed with AGS cells was quantified for all tested bacterial strains, which showed no statistically significant differences, while none of the strains caused elongation of the oral cell types (Fig. 1e-h). Bacterial binding assays demonstrated that in all cases sufficient bacteria were bound to all cell lines during infection (Fig. 1e-h). Some minor strain-dependent differences in binding capacity were observed, but these differences were not consistent with cell type (Fig. 1e-h). Thus, the lack of elongation was not a result of limited bacterial attachment to the oral epithelial cells.

\section{Lack of CagA phosphorylation in infected oral HN, CAL-27 and BHY cell lines}

Cells of the three oral cell lines and the gastric AGS cell line were infected and harvested to produce protein lysates that were analysed by Western blots. The blots were stained with antibodies specific for CagA ( $\alpha$-CagA) to check proper loading with bacteria and with $\alpha$-PY-99 antibodies that specifically detect intracellular $\mathrm{CagA}^{\mathrm{PY}}$ $[27,28]$. Antibodies recognizing $\beta$-actin were used as a protein loading control and $\mathrm{CagA} / \mathrm{CagA}{ }^{\mathrm{PY}}$ signals were quantified to determine the level of successful CagA delivery. CagA was detected in bacteria bound to all four infected cell lines, for all tested $H$. pylori wild-type strains 
a

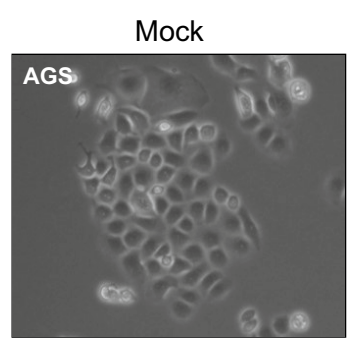

b

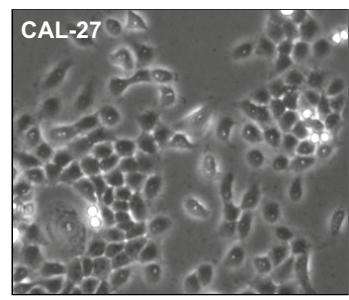

C
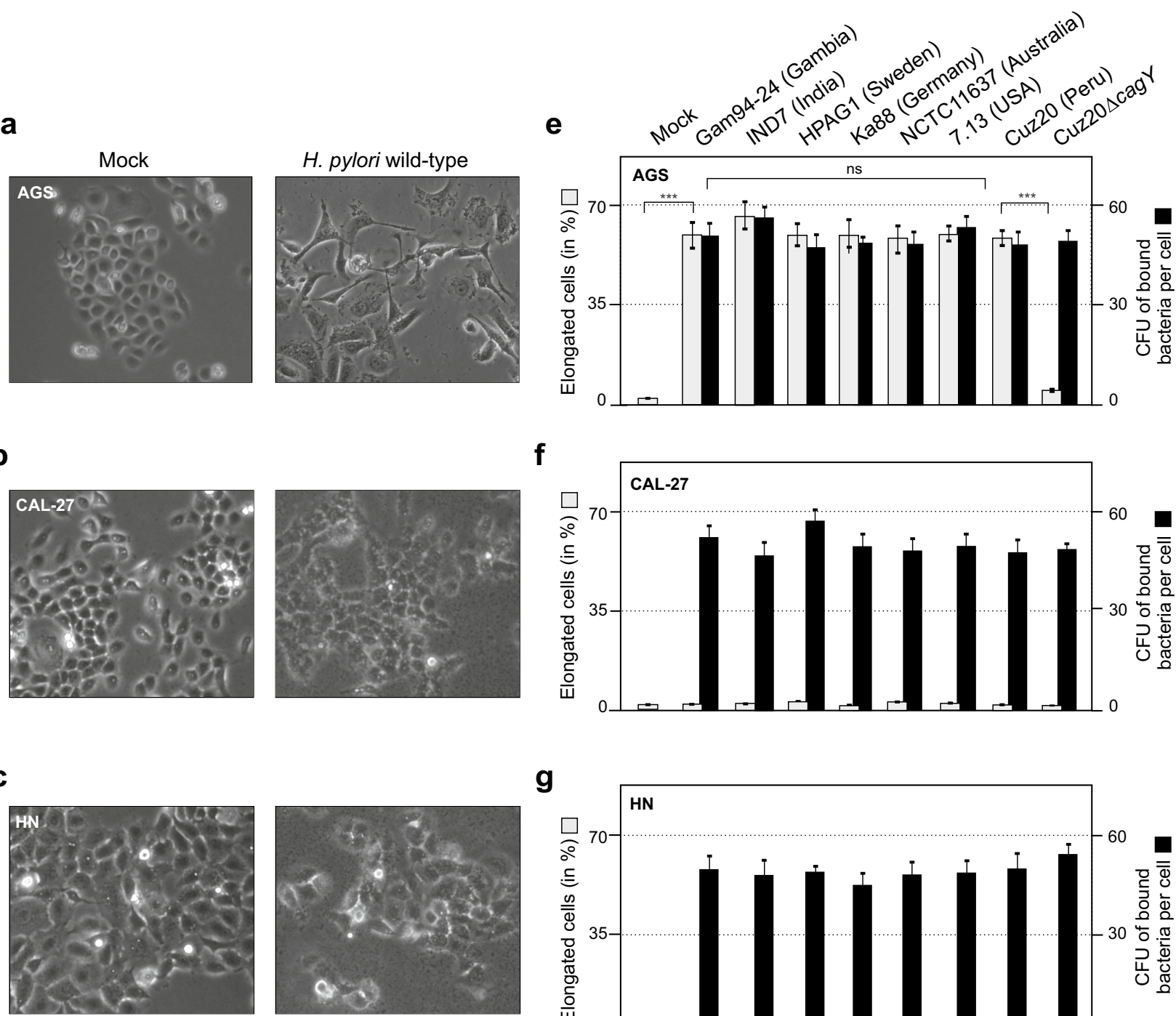

f

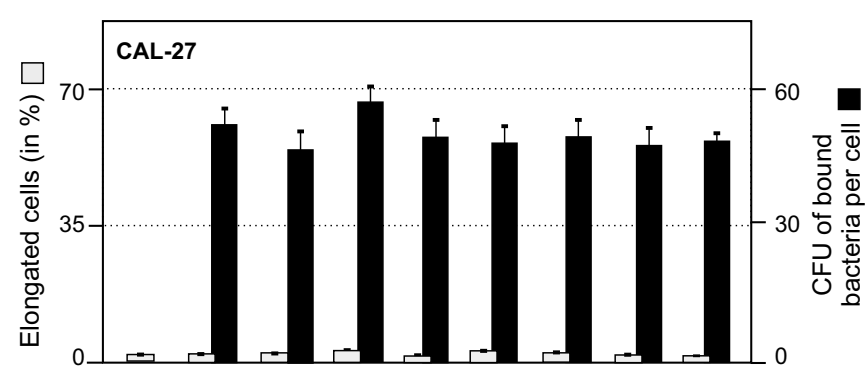

g
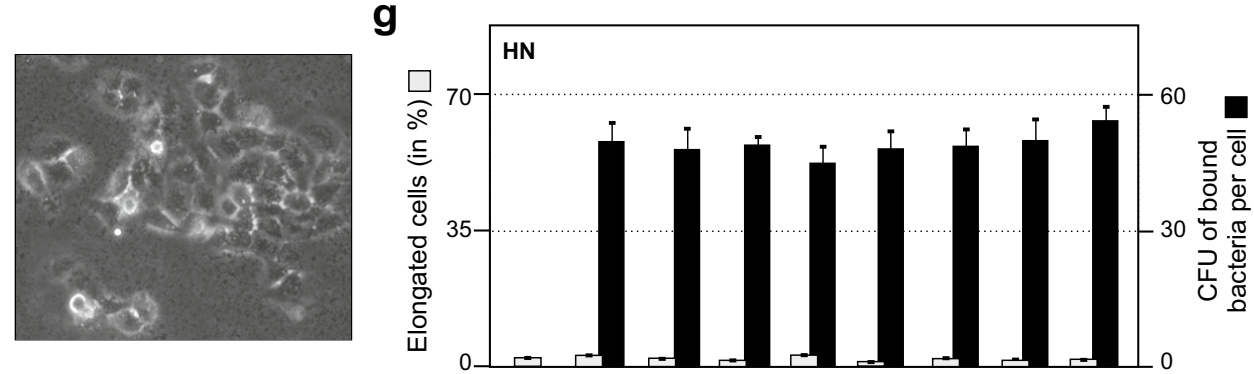

d
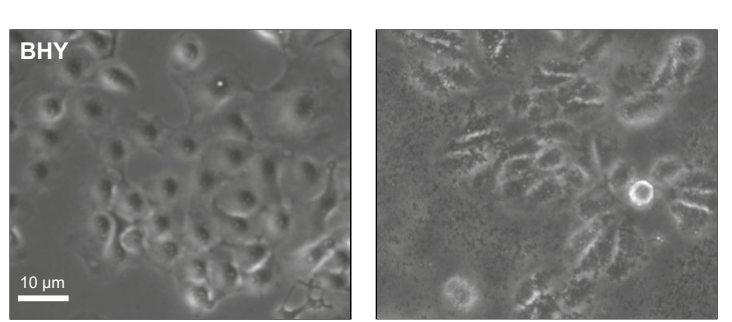

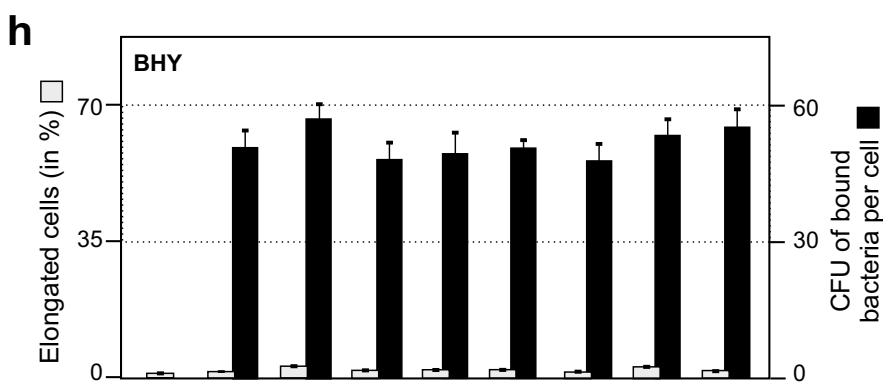

Fig. 1 Phase contrast microscopy and quantification of elongated cells of a gastric cell line and three oral epithelial cell lines infected with $H$. pylori. Adherent cells of gastric AGS (a) and oral CAL-27 (b), HN (c) and BHY (d) cells were co-incubated with H. pylori wild-type strain Gam94-24 for 6 h. Panels to the left show control cells, and to the right the corresponding infected cells are shown. Cell elongation is only visible upon infection of AGS cells. Quantitative cell elongation (grey bars) and bacterial cell binding (black bars) results from triplicate experiments are shown for AGS (e), CAL-27 (f), HN (g) and BHY (h) cells following infection with the indicated seven H. pylori wild-type strains and a $\triangle$ cag Y mutant of CUZ20 for $6 \mathrm{~h}$ (ns, not significant) 


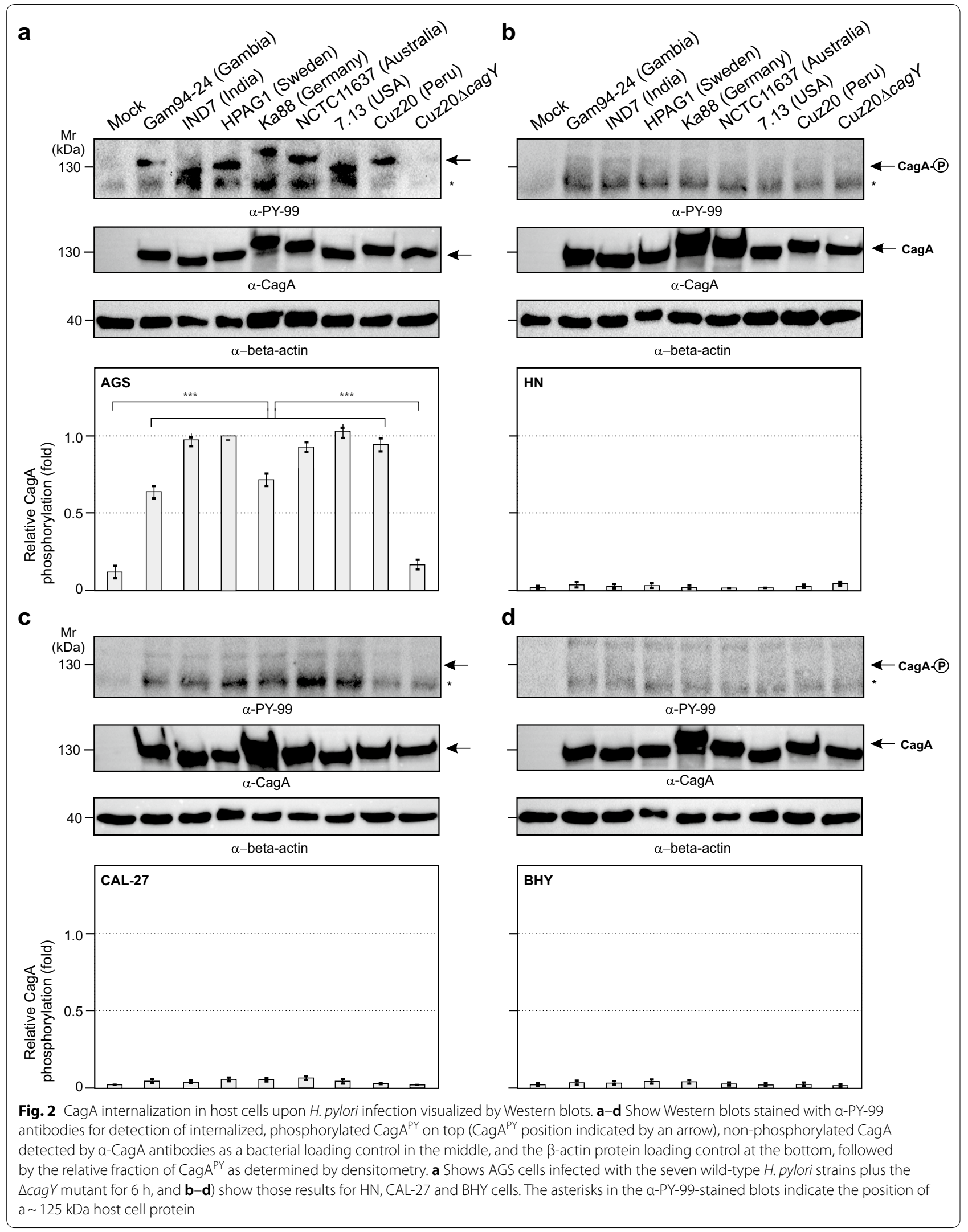


including the $\Delta \operatorname{cag} Y$ mutant, confirming that all cells had been sufficiently loaded with bacteria (Fig. 2). All wildtype $H$. pylori strains exhibited strong $\mathrm{CagA}^{\mathrm{PY}}$ signals in the AGS cells as positive control, indicating CagA was successfully delivered by these strains. Densitometric quantification revealed differences in the $\mathrm{CagA}^{\mathrm{PY}}$ levels obtained from infected AGS cells with the different bacterial strains, but these differences did not reach statistical significance (Fig. 2a). However, infected HN, CAL-27 or $\mathrm{BHY}$ cells did not result in detectable CagA ${ }^{\mathrm{PY}}$ signals, suggesting internalization of CagA had not taken place (Fig. 2b-d). The lack of $\mathrm{CagA}^{\mathrm{PY}}$ signals in the oral cell lines was confirmed in three independent experiments and shortening the infection time to $3 \mathrm{~h}$ or extending it to $12 \mathrm{~h}$ did not change these findings (data not shown). Although no CagA ${ }^{\mathrm{PY}}$ could be detected, the $\alpha$-PY-99 antibodies detected a protein band of approximately $125 \mathrm{kDa}$ (smaller than CagA, indicated by an asterisk to the side of the blots) that was readily visible in all infected gastric and oral cell lines. The band was also weakly visible in lysates of uninfected oral cells and most likely represents the host cell protein vinculin $[29,30]$.

\section{Oral HN, CAL-27 and BHY cells reveal a T4SS defect associated with CagA translocation failure}

Next, we asked if the failure of CagA phosphorylation in HN, CAL-27 or BHY cells could be due to a T4SS defect or lack of activated kinases during infection. To answer this question, we infected HN, CAL-27 or BHY cells with wild-type $H$. pylori or left the cells uninfected. After $6 \mathrm{~h}$, the cells were harvested and washed rigorously to eliminate non-bound bacteria, followed by centrifugation and resuspension in kinase phosphorylation buffer. In one sample per cell line, 1\% Nonidet P-40 (NP-40) was added to lyse the host cells with attached $H$. pylori or left untreated to keep the cells intact, respectively. These reactions were incubated at $30{ }^{\circ} \mathrm{C}$ for $30 \mathrm{~min}$, followed by harvesting and Western blotting. The resulting blots revealed that CagA from lysed cells can be profoundly phosphorylated in the presence of NP-40, but not in the non-lysed samples lacking NP-40 (Fig. 3). This implies that active kinases are present in infected HN, CAL-27 or BHY cells and lack of CagA phosphorylation is caused by compromised CagA delivery by T4SS malfunction.

\section{Infected oral HN, CAL-27 and BHY cells revealed high levels of IL-8 induction}

In the next set of experiments, we assessed if the absence of CagA internalization following bacterial binding to HN, CAL-27 and BHY cells was accompanied by impaired induction of pro-inflammatory responses that are typically mediated by other T4SS effectors such as ADP-heptose [31]. For this purpose, the supernatants of

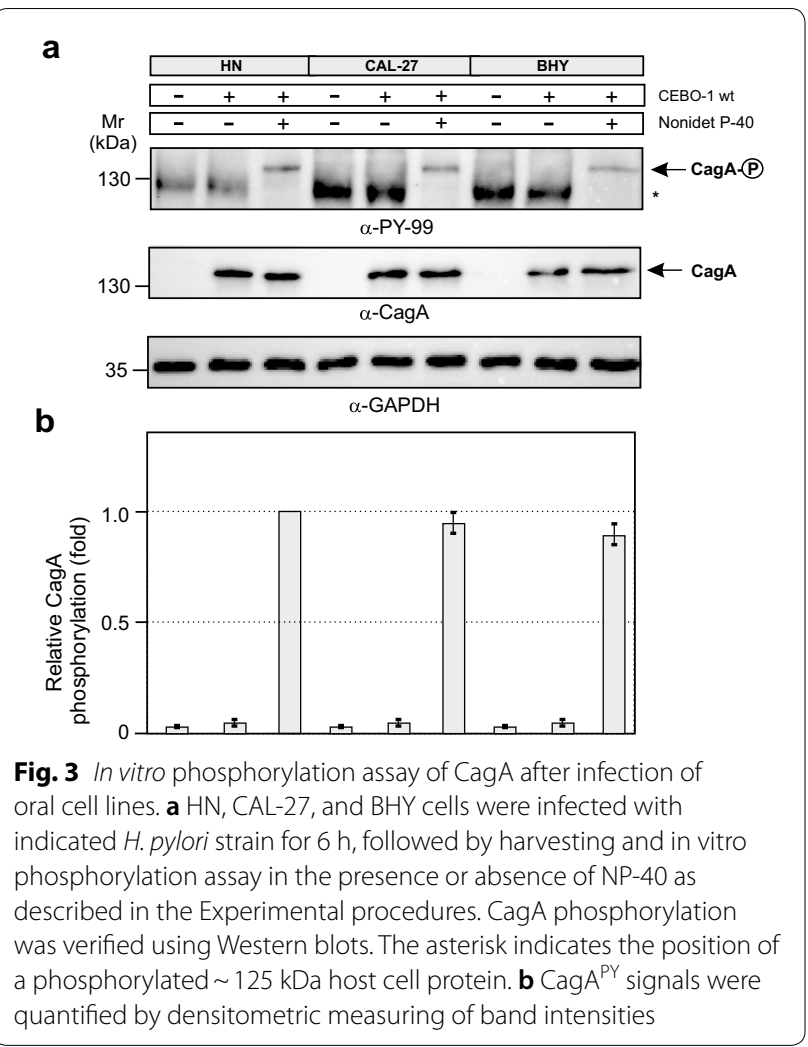

all four infected cell lines were collected and subjected to ELISA to determine the levels of induced IL-8 production. The results show that all cell lines produced high amounts of secreted IL-8 upon infection (Fig. 4). Straindependent and cell type-dependent variation in the IL-8 responses was observed that was neither significant nor consistent among the four cell lines. As expected, the CagY-negative mutant revealed significantly less IL-8 secretion for AGS, CAL-127 and BHY cells (Fig. 4a, c, d), but not for HN cells (Fig. 4b). These results suggest that pro-inflammatory responses, as exemplified by IL- 8 secretion, were induced in oral cells infected by H. pylori, even though CagA was not internalized and did not lead to cell elongation.

\section{The role of CEACAM members in CagA internalization by infected oral cells}

To elucidate why CagA was not delivered into the oral cells, we investigated whether these cell types expressed CEACAM receptors. Previous Western blotting studies had revealed that AGS cells expressed three T4SSrelevant CEACAM members, sized approximately 120 , 180 and $90 \mathrm{kDa}$, corresponding to CEACAM members 1,5 and 6 , respectively [22, 23, 26]. Here, we subjected uninfected HN, CAL-27 and BHY cells to flow cytometry and used monoclonal antibodies specific for detection 


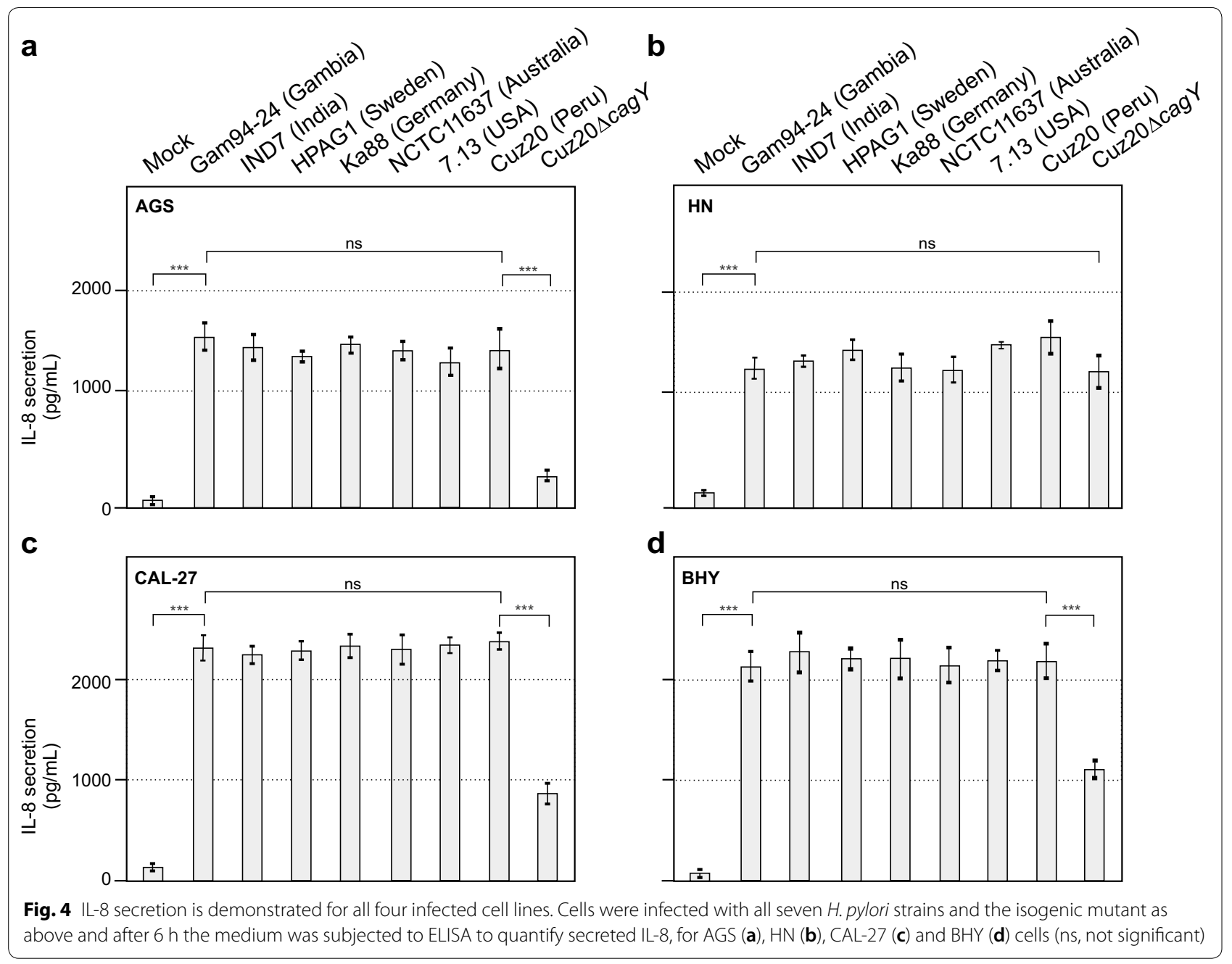

of each of these three CEACAM members (Fig. 5). The results confirmed that AGS cells indeed express all three CEACAMs (Fig. 5a), while the HN, CAL-27 and BHY cells did not produce any of those CEACAM receptors (Fig. 5b-d). This lack of CEACAM expression may, in part or completely, account for the lack of CagA internalization in these oral epithelial cell lines. To investigate this further, the oral cells were transfected with plasmid constructs expressing either CEACAM1, 5 or 6 as previously described [26] and these transfected cells were infected with $H$. pylori. Expression of the three CEACAM receptors by the transfected cell lines was confirmed by Western blotting using monoclonal antibody 6G5j recognizing CEACAM1, 5 and 6 (Fig. 6). When these cells expressing a single CEACAM type were infected with $H$. pylori, $\mathrm{CagA}^{\mathrm{PY}}$ signals were clearly visible in cell lysates following staining with PY-99 antibodies (Fig. 6, top). The intensity of the obtained $\mathrm{CagA}^{\mathrm{PY}}$ signals demonstrated that there were no significant differences for the three CEACAM types resulting in CagA internalization, in either of the three cell lines, and that the fraction of intracellular CagA was similar to that obtained with AGS cells (cf. Fig. 2). This demonstrates that the reason CagA was not internalized by the oral cell lines (as per Fig. 2) is due to their lack of CEACAM expression. Interestingly, CEACAM expression in oral cells followed by infection with $H$. pylori did not rescue the elongation phenotype, suggesting the existence of yet unknown AGS gastric epithelial cell-specific features that are absent in HN, CAL27 and BHY cell lines.

\section{Discussion}

During gastric infection, $H$. pylori interacts with its host by means of various factors, including VacA, CagA and T4SS-injected effector molecules. Their roles in bacterial colonization, persistence and development of gastric disease have been studied in detail [1, 2, 32, 33]. This has led to a model of host-pathogen interactions that starts with the activity of BabA and SabA adhesins that initiate and sustain contact to the host cell's Lewis 







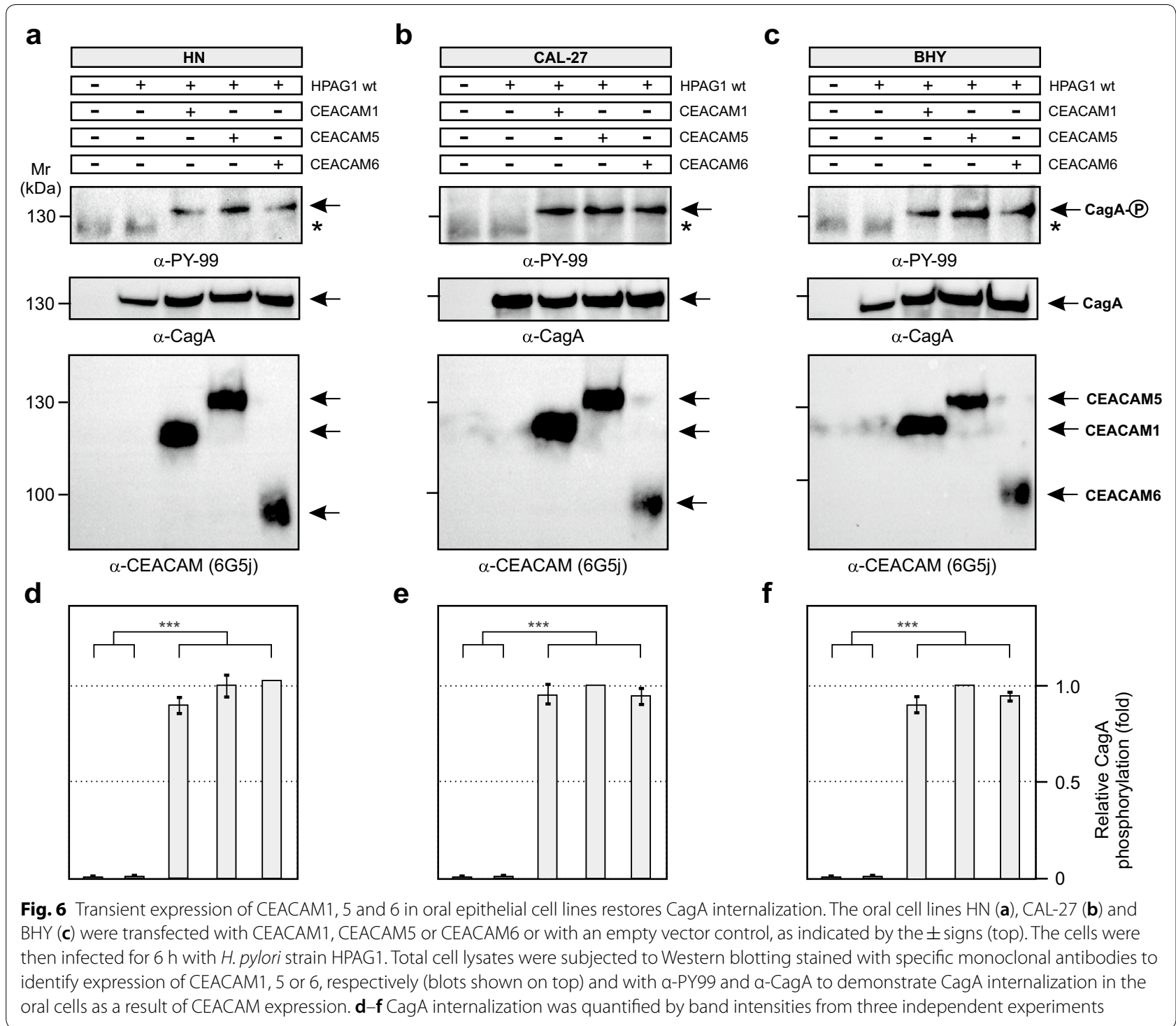

antigens $[20,21]$. The bacterial T4SS then binds to factors on the surface of the host cell to enable intercellular delivery of CagA. A role of integrin- $\beta_{1}$, phosphatidylserine and cholesterol has been implicated in T4SSdependent CagA injection [17, 34-39], but of crucial importance are the CEACAM receptors and their bacterial ligand HopQ, as they need to interact for full functionality of the $H$. pylori T4SS [21-26]. We have recently proposed that HopQ binding to CEACAM molecules may bring the T4SS-pilus in the optimal position and distance to allow delivery of CagA [26]. Most of those observations were made with the gastric cell line AGS. In the present study, we investigated the interactions between $H$. pylori and three oral epithelial cell lines (HN, CAL-27 and BHY), which confirmed the dependence on CEACAM receptors for CagA intracellular delivery. We found that these oral cell lines did not express CEACAM receptors naturally, while infecting the cells in vitro with T4SS-positive wild-type strains of $\mathrm{H}$. pylori did not result in CagA intracellular delivery or pathogenic effects. Intracellular CagA delivery, however, could be rescued by genetic introduction of single representatives of T4SS-relevant CEACAM members, which now resulted in internalized and phosphorylated CagA. Obviously, the lack of CEACAM members is not the only difference between the studied gastric and oral epithelial cell lines, which explains why restoration of CagA delivery and phosphorylation in the oral cells by means of CEACAM expression did not result in cell elongation upon $H$. pylori infection that is typical for 
infected gastric AGS cells (Fig. 1). The reason for this is currently under investigation.

Similar to the oral cell lines analyzed here, several previous in vivo studies showed that CEACAMs are not or only barely expressed in the healthy oral epithelium and other cell types of the oral mucosa [40, 41]. However, a spatiotemporal CEACAM expression during the embryonic development of the oral epithelium or as a consequence of oral infection with certain bacteria such as Fusobacter spp. in connection with inflammatory reactions has been reported [42, 43]. Increased CEACAM expression was also described for other pathological scenarios in the oral cavity such as in oral lichen planus patients or in smokers $[44,45]$. CEACAM1 was also shown to be overexpressed in oral tumors [40]. Ultimately, the pathological induction of CEACAM expression in the oral cavity may further exacerbate the situation in the presence of $H$. pylori, since CagA could then be translocated into the cells leading to a further deterioration in health condition of the patient. Unfortunately, there are no in vivo data yet to support this idea. Therefore, studies addressing this interesting hypothesis should be subject of future studies.

Oral epithelial cell lines are not the only cell types resistant to CagA translocation and phosphorylation, as this was also demonstrated for other non-gastric cell lines (e.g. HEK293, CHO) and gastric cell line MKN28, which also happens to completely lack CEACAM expression $[22-24,46]$. Similar to the findings reported here for oral cell lines, sensitivity to CagA can be introduced in these cell lines by prior transfection with CEACAM1, 5 or $6[22,23]$. Recently, we further demonstrated that duodenal AZ-521 cells do not permit CagA translocation, despite producing integrin- $\beta_{1}[26,47]$ phosphatidylserine [48], and cholesterol (our unpublished data). Again, these cells completely lack expression of CEACAM members, but in contrast to the observations made with the abovementioned cell types and the oral cell lines, only transfection of AZ-521 cells with CEACAM1 or CEACAM5 induced CagA sensitivity, while expression of CEACAM6 had no effect [26]. In contrast, HeLa cells (a cervical adenocarcinoma cell line) lack expression of CEACAM1, 3, 5 and 6, but these cells are sensitive to delivery and phosphorylation of CagA $[49,50]$. In this case, CagA internalization may result from an alternative mechanism, as it was further shown that CagA could be internalized by HeLa cells when delivered by a hop $Q$ deletion mutant [50]. This contrasts with observations made with AGS, Caco-2, MKN45 or other CEACAM-expressing gastrointestinal cell lines that all require bacterial HopQ to interact with CEACAM receptors for profound T4SSdependent CagA delivery [22-24, 46].
The strong induction of pro-inflammatory responses through means of IL- 8 secretion by all infected oral epithelial cell lines is surprising. Usually, T4SS-dependent CagA translocation and inflammation are coupled processes that occur at the same time [51, 52]. However, it was recently shown that HopQ, which can bind to a specific subset of CEACAMs, promotes canonical NF- $\mathrm{KB}$ activation and IL-8 secretion in AGS and NCI-N87 cells, but not in HeLa cells, which are devoid of the CEACAMs [50]. Thus, it seems that $H$. pylori can activate CEACAMdependent and CEACAM-independent pathways of NF- $\mathrm{KB}$ activation and IL- 8 secretion depending on the cell line. The same maybe true for strong IL- 8 induction in the CEACAM-deficient HN, CAL-27 and BHY cell lines. It also appears remarkable that while $H$. pylori-triggered IL-8 secretion was T4SS-dependent in CAL-27 and BHY cells, this was not the case in HN cells. In the latter cell line, the T4SS-deficient $\operatorname{Cuz} \Delta \operatorname{cag} Y$ mutant produced similar high IL-8 levels compared to wild-type infections. The reason for this difference is unclear. We propose that a yet unknown non-canonical T4SS-independent NF- $k B$ pathway is induced in infected $\mathrm{HN}$ cells. It will be interesting to investigate this specific signal transduction cascade in forthcoming studies.

\section{Conclusions}

The work performed here clearly demonstrates that cell lines obtained from the oral epithelium are resistant to T4SS-dependent injection of CagA by H. pylori, similarly to most CEACAM-negative cells (except for HeLa) and that this resistance is overcome by genetic introduction and expression of single CEACAM types. These findings have implications for potential oral colonization by $H$. pylori. The oral cavity is actually considered as a temporary habitat during transmission of gastric $H$. pylori from person to person [1-7]. This assumption is in agreement with our present finding that a major docking site of $H$. pylori is missing on the oral epithelium. Furthermore, the absence of CEACAMs on the surface of healthy oral epithelial cells would result in the lack of T4SS-related pathogenic effects through injected CagA of otherwise highly virulent strains. However, since an immune response in these cells would still be elicited (as demonstrated here by IL- 8 production) it cannot be excluded that presence of $H$. pylori in the oral cavity may lead to local inflammatory reactions, similar to their activities in the stomach. This idea needs to be investigated in future research.

\section{Methods}

\section{Cell lines and tissue cultures}

The oral cell lines were all from squamous cell carcinomas. Cell line HN (ACC 417; DSMZ Braunschweig/ Germany) was derived from a patient with an invasive 
tumour of the soft palate, although the cell line was isolated from a tumour of the cervical lymph node 7 years after initial treatment of the primary tumour. The CAL27 cell line (ATCC CRL-2095 ${ }^{\mathrm{TM}}$ ) was from a tumour of the tongue, and the BHY cell line (ACC 404, DSMZ) was derived from a squamous cell carcinoma of the lower alveolus that had invaded to the mandibular bone and muscle layer of the oral floor.

These cell lines, together with the human gastric adenocarcinoma cell line AGS (ATCC CRL-1739 ${ }^{\mathrm{TM}}$ ) were cultured in RPMI 1640 medium with $10 \%$ heat-inactivated foetal calf serum (Gibco, Paisley, UK), 2 mM L-glutamine (Invitrogen, Karlsruhe, Germany) and 1\% antibiotic/antimycotic solution (Sigma-Aldrich) at $37{ }^{\circ} \mathrm{C}$ under $5 \% \mathrm{CO}_{2}$. Cells were subcultured at a ratio of $1: 3-5$ every $2-3$ days at 70 to $90 \%$ confluence. All cells were maintained in $75 \mathrm{~cm}^{2}$ tissue culture flasks and seeded into 6-well plates (Greiner-Bio-One, Germany) to reach approximately $3.5 \times 10^{5}$ cells per well (about $80 \%$ confluency) for infection experiments.

The HN, CAL-27 and BHY cells were transfected and then cultivated for $48 \mathrm{~h}$ with human CEACAM1, CEACAM5 and CEACAM6 expression constructs or an empty vector control using previously described experimental procedure $[23,26]$.

\section{H. pylori strains and culture conditions}

The H. pylori strains utilized in this report, strains Gam94-24, IND7, HPAG1, Ka88, NCTC11637, 7.13 and Cuz20, all contained the cagPAI [27, 28, 53, 54]. The strain CEBO-1 was cultivated from a patient from the Phillipines with gastritis (this study). An isogenic $\Delta c a g Y$ mutant of Cuz20 was produced as previously described [26] and was selected and grown in presence of $4 \mu \mathrm{g} / \mathrm{mL}$ chloramphenicol. All H. pylori strains were cultivated from glycerol stocks on GC agar plates containing 5\% horse serum, $5 \mu \mathrm{g} / \mathrm{mL}$ trimethoprim, $10 \mu \mathrm{g} / \mathrm{mL}$ vancomycin and $1 \mu \mathrm{g} / \mathrm{mL}$ nystatin [30]. The agar plates were incubated in jars in an atmosphere of $85 \% \mathrm{~N}_{2}, 10 \% \mathrm{CO}_{2}$ and $5 \% \mathrm{O}_{2}$ (Oxoid, Wesel/Germany) at $37{ }^{\circ} \mathrm{C}$ for 2 days.

Experimental infection of cells and bacterial binding assays Bacteria ( $H$. pylori wild-type strains and the isogenic $\Delta c a g Y$ Cuz20 mutant) were harvested from agar plates using sterile cotton swabs (Carl Roth, Karlsruhe/Germany) and resuspended in phosphate buffered saline, $\mathrm{pH}$ 7.4 (PBS) at concentrations of identical $\mathrm{OD}_{600}$. The exact numbers of colony-forming units (CFU) was established by plating serial dilutions on agar plates [55]. Cells were washed with once with PBS and culture medium devoid of antibiotics or antimycotics and $H$. pylori was added at an MOI of 100 (approximately $3.5 \times 10^{7} \mathrm{CFU} /$ well) in all experiments. The cells were then incubated for $6 \mathrm{~h}$ as reported previously [56]. An uninfected mock control was included where PBS lacking bacteria was added.

For binding assays, after $6 \mathrm{~h}$ of incubation the cells were washed three times with $1 \mathrm{~mL}$ of pre-warmed culture medium without antibiotics to eliminate non-attached bacteria, after which the cells were lysed by incubation with $1 \mathrm{~mL} 0.1 \%$ saponin in PBS at $37^{\circ} \mathrm{C}$ for $15 \mathrm{~min}$ [57]. After collection serial dilutions of the cell lysates were cultivated on GC agar plates for quantification of cellbound H. pylori CFU.

\section{In vitro CagA phosphorylation assay}

After infecting approximately $3.5 \times 10^{5} \mathrm{HN}, \mathrm{CAL}-27$ or BHY cells with wild-type $H$. pylori for $6 \mathrm{~h}$, the cells were harvested with a cell scraper in ice-cold kinase buffer (150 mM NaCl, $25 \mathrm{mM}$ HEPES, pH 7.0, $5 \mathrm{mM}$ dithiothreitol, $10 \mathrm{mM} \mathrm{MgCl}, 1 \mathrm{mM} \mathrm{Na}_{3} \mathrm{VO}_{4}, 1 \times$ Complete $^{\mathrm{TM}}$ proteinase inhibitor mix) followed by two washing steps and centrifugation at $500 \times g$ to remove unbound bacteria $[26,58]$. Using a pipette, each pellet was then gently mixed with $200 \mu \mathrm{L}$ fresh kinase buffer or kinase buffer containing 1\% NP-40 (Sigma-Aldrich) for cell lysis. ATP $(1 \mathrm{mM})$ was added to start the in vitro phosphorylation reaction for $30 \mathrm{~min}$ at $30{ }^{\circ} \mathrm{C}$. Uninfected cells were used as negative control. The reactions were terminated by adding $60 \mu \mathrm{L} 4 \times$ reducing SDS-PAGE buffer $(10 \%$ SDS, $10 \%$ mercaptoethanol, $200 \mathrm{mM}$ Tris- $\mathrm{HCl}, \mathrm{pH} 6.8,0.4 \%$ bromphenol blue, $40 \%$ glycerol) followed by $5 \mathrm{~min}$ boiling and Western blotting analyses.

\section{Phase contrast microscopy}

Phase contrast images of infected cells were obtained with a Leica DMI4000B microscope. Cell elongation as a result of infection was quantified using criteria for elongation as described previously $[51,59]$ to be scored as elongated thin cell protrusions with sizes between 20 and $70 \mu \mathrm{m}$ had to be present. Protrusions shorter than $10 \mu \mathrm{m}$ were ignored. The experiments were performed in triplicate. All images were read in a blinded manner.

\section{Flow cytometry for detection of CEACAM expression}

To analyse CEACAM expression, cells from all four cell lines were harvested during log phase growth and after reaching confluence. The cells were stained with monoclonal antibodies $\alpha$-CEACAM1, $\alpha$-CEACAM5, $\alpha$-CEACAM6 and isotype-matched control antibodies, followed by FITC-conjugated secondary antibody. Subsequently, samples were analysed by flow cytometry as previously described [26]. 


\section{Western blotting}

Infected cells (produced as described above) were harvested, mixed with an equal volume of $2 \times$ SDS-PAGE buffer and lysed at $100{ }^{\circ} \mathrm{C}$ for $5 \mathrm{~min}$. The cell lysates were then separated by $6-12 \%$ gradient SDS-PAGE, and Western blotted onto PVDF membranes (Immobilon$\mathrm{P}$, Merck Millipore). Prior to staining the membranes were blocked with $25 \mathrm{mM}$ Tris- $\mathrm{HCl} \mathrm{pH} \mathrm{7.4,} 140 \mathrm{mM}$ $\mathrm{NaCl}, 0.1 \%$ Tween-20, 3\% BSA for $1 \mathrm{~h}$ at $20{ }^{\circ} \mathrm{C}$. CagA protein was detected with rabbit polyclonal $\alpha$-CagA antibody (\# HPP-5003-9, Austral Biologicals, San Ramon/ USA) and $\alpha$-rabbit polyvalent goat secondary antibody (\# 31462, Thermo Fisher Scientific, Massachusetts/ USA). Phosphorylated CagA ( $\mathrm{CagA}^{\mathrm{PY}}$ ) was detected by $\alpha$-PY-99 mouse antibodies and $\beta$-actin with monoclonal mouse antibodies (\# A5441, Sigma-Aldrich), followed by $\alpha$-mouse goat antibodies (\# 31446). Monoclonal antibody $\alpha$-CEACAM (6G5j) recognizes CEACAM1, CEACAM5 and CEACAM6 and has been described elsewhere [23]. Secondary antibodies were conjugated with horseradish peroxidase (Thermo Fisher Scientific, Massachusetts/ USA) and detected with the ECL Plus chemiluminescence Western Blot kit (GE Healthcare).

Densitometric analysis for quantification of band intensity was performed with Image Lab software (BioRad, Munich/Germany) and following normalization of band intensities, the ratio of $\mathrm{CagA}^{\mathrm{PY}}$ over CagA signal was plotted for each lane [26].

\section{ELISA for detection of IL-8}

All four cell lines were infected with the seven $H$. pylori strains and the deletion mutant as described above. After $6 \mathrm{~h}$ the cell medium was collected and subjected to ELISA to quantify secreted IL-8, using a commercially available assay kit (Becton-Dickinson, Germany).

\section{Statistical data analysis}

Every experiment was performed in triplicate and statistical significance was calculated with GraphPad Prism statistical software (version 8.0). Data were evaluated via one-way ANOVA followed by Tukey's multiple comparison test. Significant difference was defined by ${ }^{*} \mathrm{p} \leq 0.05$, *** $\mathrm{p} \leq 0.01$, and ${ }^{* * *} \mathrm{p} \leq 0.001$.

\begin{abstract}
Abbreviations
CagA AY: Phosphorylated CagA; CEACAM: Carcinoembryonic antigen-related cell adhesion molecule; CFU: Colony forming units; MOI: Multiplicity of infection; NP-40: Nonidet P-40; PAI: Pathogenicity island; PBS: Phophate buffered saline; T4SS: Type-IV secretion system; a-CagA: Antibodies specific for CagA.
\end{abstract}

\section{Acknowledgements}

We thank Wilhelm Brill and Nina Rottmann for excellent technical assistance.

\section{Authors' contributions}

NT and SB developed the design and concept of the study. NT, TDG, VS, TR MCCC and EMB obtained the data. NT, SB, HLG, BBS and CH were involved in analysis and interpretation of the data. NT and SB wrote the paper. All authors read and approved the final manuscript.

\section{Funding}

This work was partly supported by the German Research Foundation (DFG project TE776/3-1 for NT and SI-1558/3-1 for BBS). The funders had no role in study design, data collection and analysis, decision to publish, or preparation of the manuscript.

\section{Availability of data and materials}

The datasets used and/or analysed during the current study are available from the corresponding author on reasonable request.

\section{Ethics approval and consent to participate}

Not applicable.

\section{Consent for publication \\ Not applicable.}

\section{Competing Interests}

None declared for all authors.

\section{Author details}

${ }^{1}$ Department of Biology, Division of Microbiology, Friedrich Alexander University Erlangen, Staudtstrasse 5, 91058 Erlangen, Germany. ${ }^{2}$ Medical Faculty, Institute of Anatomy, University of Duisburg-Essen, Hufelandstrasse 55, 45147 Essen, Germany. ${ }^{3}$ Division of Clinical and Experimental Oral Medicine, Department of OMF-Surgery, Leipzig University Hospital, University of Leipzig, Leipzig, Germany. ${ }^{4}$ Center for Basic Science Research (CBSR), Research and Biotechnology (R\&B), St. Luke's Medical Center, Quezon City, Philippines. ${ }^{5}$ Institute for Digestive and Liver Diseases, St. Luke's Medical Center, Quezon City, Philippines. ${ }^{6}$ Department of Oral, Maxillary, Facial and Reconstructive Plastic Surgery, University Hospital of Leipzig, Leipzig, Germany. ${ }^{7}$ Department of Paediatric Dentistry, University School of Dental Medicine, University of Leipzig, Leipzig, Germany.

Received: 6 February 2020 Accepted: 9 May 2020

Published online: 14 May 2020

\section{References}

1. Amieva M, Peek RM Jr. Pathobiology of Helicobacter pylori-induced gastric cancer. Gastroenterol. 2016;150:64-78.

2. Ansari S, Yamaoka Y. Helicobacter pylori virulence factors exploiting gastric colonization and its pathogenicity. Toxins (Basel). 2019;11(11):E677.

3. Goodwin CS, Mendall MM, Northfield TC. Helicobacter pylori infection. Lancet. 1997;349:265-9.

4. Parsonnet J, Shmuely H, Haggerty T. Fecal and oral shedding of Helicobacter pylori from healthy infected adults. JAMA. 1999;282(23):2240-5.

5. Kayali S, Manfredi M, Gaiani F, Bianchi L, Bizzarri B, Leandro G, et al. Helicobacter pylori, transmission routes and recurrence of infection: state of the art. Acta Biomed. 2018;89(8-S):72-6.

6. Nguyen AM, El-Zaatari FA, Graham DY. Helicobacter pylori in the oral cavity. A critical review of the literature. Oral Surg Oral Med Oral Pathol Oral Radiol Endod. 1995;79:705-9.

7. Hirsch C, Tegtmeyer N, Rohde M, Rowland M, Oyarzabal OA, Backert S Live Helicobacter pylori in the root canal of endodontic-infected deciduous teeth. J Gastroenterol. 2012;47:936-40.

8. Malaty HM, Evans DJ Jr, Abramovitch K, Evans DG, Graham DY. Helicobacter pylori in dental workers: a seroepidemiology study. Am J Gastroenterol. 1992;87:1728-31.

9. Nguyen AMH, Engstrand L, Genta RM, Graham DY, El-Zaatari FA. Detection of Helicobacter pylori in dental plaque by reverse transcription-polymerase chain reaction. J Clin Microbiol. 1993;31:783-7.

10. Zou QH, Li RQ. Helicobacter pylori in the oral cavity and gastric mucosa: a meta-analysis. J Oral Pathol Med. 2011;40:317-24. 
11. Covacci A, Telford JL, Del Giudice G, Parsonnet J, Rappuoli R. Helicobacter pylori virulence and genetic geography. Science. 1999;284(5418):1328-33.

12. Hayashi T, Senda M, Morohashi H, Higashi H, Horio M, Kashiba Y, et al. Tertiary structure-function analysis reveals the pathogenic signaling potentiation mechanism of Helicobacter pylori oncogenic effector CagA. Cell Host Microbe. 2012;12:20-33.

13. Smolka AJ, Backert S. How Helicobacter pylori infection controls gastric acid secretion. J Gastroenterol. 2012;47:609-18.

14. Grohmann E, Christie PJ, Waksman G, Backert S. Type IV secretion in Gramnegative and Gram-positive bacteria. Mol Microbiol. 2018;107(4):455-71.

15. Chung JM, Sheedlo MJ, Campbell AM, Sawhney N, Frick-Cheng AE, Lacy DB, et al. Structure of the Helicobacter pylori Cag type IV secretion system. Elife. 2019;8:e47644

16. Segal ED, Cha J, Lo J, Falkow S, Tompkins LS. Altered states: involvement of phosphorylated CagA in the induction of host cellular growth changes by Helicobacter pylori. Proc Natl Acad Sci USA. 1999;96:14559-64.

17. Backert S, Tegtmeyer N, Fischer W. Composition, structure and function of the Helicobacter pylori cag pathogenicity island encoded type IV secretion system. Future Microbiol. 2015;10:955-65.

18. Backert S, Haas R, Gerhard M, Naumann M. The Helicobacter pylori type IV secretion system encoded by the cag pathogenicity island: architecture, function, and signaling. Curr Top Microbiol Immunol. 2017;413:187-220.

19. Backert S, Feller SM, Wessler S. Emerging roles of Abl family tyrosine kinases in microbial pathogenesis. Trends Biochem Sci. 2008;33:80-90.

20. Dubois A, Boren T. Helicobacter pylori is invasive and it may be a facultative intracellular organism. Cell Microbiol. 2007;9:1108-16.

21. Bonsor DA, Sundberg EJ. Roles of adhesion to epithelial cells in gastric colonization by Helicobacter pylori. Adv Exp Med Biol. 2019;1149:57-75.

22. Königer $V$, Holsten $L$, Harrison U, Busch B, Loell E, Zhao Q, et al. Helicobacter pylori exploits human CEACAMs via HopQ for adherence and translocation of CagA. Nat Microbiol. 2016;2:16188.

23. Javaheri A, Kruse T, Moonens K, Mejias-Luque R, Debraekeleer A, Asche Cl, et al. Helicobacter pylori adhesin HopQ engages in a virulence-enhancing interaction with human CEACAMs. Nat Microbiol. 2016;2:16189.

24. Moonens C, Hamway Y, Neddermann M, Reschke M, Tegtmeyer N, Kruse $\mathrm{T}$, et al. Helicobacter pylori adhesin HopQ disrupts trans dimerization in human CEACAMs. EMBO J. 2018;37:e98665.

25. Bonsor DA, Zhao Q, Schmidinger B, Weiss E, Wang J, Deredge D, et al. The Helicobacter pylori adhesin protein HopQ exploits the dimer interface of human CEACAMs to facilitate translocation of the oncoprotein CagA. EMBO J. 2018;37(13):e98664.

26. Tegtmeyer N, Harrer A, Schmitt $V$, Singer BB, Backert S. Expression of CEACAM1 or CEACAM5 in AZ-521 cells restores the type IV secretion deficiency for translocation of CagA by Helicobacter pylori. Cell Microbiol. 2019;21(1):e12965.

27. Lind J, Backert S, Pfleiderer K, Berg DE, Yamaoka Y, Sticht H, et al. Systematic analysis of phosphotyrosine antibodies recognizing single phosphorylated EPIYA-motifs in CagA of Western-type Helicobacter pylori strains. PLOS ONE. 2014;9:e96488.

28. Lind J, Backert S, Hoffmann R, Eichler J, Yamaoka Y, Perez-Perez Gl, et al. Systematic analysis of phosphotyrosine antibodies recognizing single phosphorylated EPIYA-motifs in CagA of East Asian-type Helicobacter pylori strains. BMC Microbiol. 2016;16:201.

29. Bays JL, DeMali KA. Vinculin in cell-cell and cell-matrix adhesions. Cell Mol Life Sci. 2017;74:2999-3009.

30. Moese S, Selbach M, Brinkmann V, Karlas A, Haimovich B, Backert S, et al. The Helicobacter pylori CagA protein disrupts matrix adhesion of gastric epithelial cells by dephosphorylation of vinculin. Cell Microbiol. 2007;9:1148-61.

31. Pfannkuch L, Hurwitz R, Traulsen J, Sigulla J, Poeschke M, Matzner L, et al. ADP heptose, a novel pathogen-associated molecular pattern identified in Helicobacter pylori. FASEB J. 2019;33(8):9087-99.

32. Boquet P, Ricci V. Intoxication strategy of Helicobacter pylori VacA toxin. Trends Microbiol. 2012;20:165-74.

33. Naumann M, Sokolova O, Tegtmeyer N, Backert S. Helicobacter pylori: a paradigm pathogen for subverting host cell signal transmission. Trends Microbiol. 2017;25:316-28.

34. KwokT, Zabler D, Urman S, Rohde M, Hartig R, Wessler S, et al. Helicobacter exploits integrin for type IV secretion and kinase activation. Nature. 2007;449:862-6.
35. Lai CH, Chang YC, Du SY, Wang HJ, Kuo CH, Fang SH, et al. Cholesterol depletion reduces Helicobacter pylori CagA translocation and CagAinduced responses in AGS cells. Infect Immun. 2008;76:3293-303.

36. Posselt G, Backert S, Wessler S. The functional interplay of Helicobacter pylori factors with gastric epithelial cells induces a multi-step process in pathogenesis. Cell Commun Signal. 2013;11:77.

37. Conradi J, Tegtmeyer N, Woźna M, Wissbrock M, Michalek C, Gagell C, et al. An RGD helper sequence in CagL of Helicobacter pylori assists in interactions with integrins and injection of CagA. Front Cell Infect Microbiol. 2012;2:70.

38. Barden S, Schomburg B, Conradi J, Backert S, Sewald N, Niemann HH. Structure of a three-dimensional domain-swapped dimer of the Helicobacter pylori type IV secretion system pilus protein CagL. Acta Crystallogr D Biol Crystallogr. 2014;70(Pt 5):1391-400.

39. Barden S, Lange S, Tegtmeyer N, Conradi J, Sewald N, Backert S, et al. A helical RGD motif promoting cell adhesion: crystal structures of the Helicobacter pylori type IV secretion system pilus protein CagL. Structure. 2013;21:1931-41.

40. Wang FF, Guan BX, Yang JY, Wang HT, Zhou CJ. CEACAM1 is overexpressed in oral tumors and related to tumorigenesis. Med Mol Morphol. 2017;50(1):42-51.

41. Simonetti O, Lucarini G, Rubini C, Zizzi A, Aspriello SD, Di Primio R, et al. Correlation between immunohistochemical staining of CEACAM1 and clinicopathological findings in oral pre-neoplastic lesions and squamous cell carcinoma. Med Mol Morphol. 2018;51:41-7.

42. Mima J, Koshino A, Oka K, Uchida H, Hieda Y, Nohara K, et al. Regulation of the epithelial adhesion molecule CEACAM1 is important for palate formation. PLoS ONE. 2013;8:e61653.

43. Brewer ML, Dymock D, Brady RL, Singer BB, Virji M, Hill DJ. Fusobacterium spp. target human CEACAM1 via the trimeric autotransporter adhesin CbpF. J Oral Microbiol. 2019:11(1):1565043.

44. Liu GX, Xie Q, Zhou CJ, Zhang XY, Ma BL, Wang CQ, et al. The possible roles of OPN-regulated CEACAM1 expression in promoting the survival of activated $T$ cells and the apoptosis of oral keratinocytes in oral lichen planus patients. J Clin Immunol. 2011;31:827-39.

45. Boyle JO, Gümüs ZH, Kacker A, Choksi VL, Bocker JM, Zhou XK, et al. Effects of cigarette smoke on the human oral mucosal transcriptome. Cancer Prev Res (Phila). 2010;3:266-78.

46. Kumar Pachathundikandi S, Brandt S, Madassery J, Backert S. Induction of TLR-2 and TLR-5 expression by Helicobacter pylori switches cagPAldependent signalling leading to the secretion of IL-8 and TNF-a. PLoS ONE. 2011:6:e19614.

47. Jimenez-Soto LF, Kutter S, Sewald X, Ertl C, Weiss E, Kapp U, et al. Helicobacter pylori type IV secretion apparatus exploits beta1 integrin in a novel RGD-independent manner. PLoS Pathog. 2009;5:e1000684.

48. Tegtmeyer N, Backert S. Helicobacter pylori infection of AZ-521 cells reveals a type IV secretion defect and VacA-independent CagA phosphorylation. Dis Model Mech. 2017;10:1539-40.

49. Bauer B, Moese S, Bartfeld S, Meyer TF, Selbach M. Analysis of cell typespecific responses mediated by the type IV secretion system of Helicobacter pylori. Infect Immun. 2005;73:4643-52.

50. Feige MH, Sokolova O, Pickenhahn A, Maubach G, Naumann M. HopQ impacts the integrin a5 $\beta 1$-independent NF-kB activation by Helicobacter pylori in CEACAM expressing cells. Int J Med Microbiol. 2018;308:527-33.

51. Fischer W, Püls J, Buhrdorf R, Gebert B, Odenbreit S, Haas R. Systematic mutagenesis of the Helicobacter pylori cag pathogenicity island: essential genes for CagA translocation in host cells and induction of interleukin-8. Mol Microbiol. 2001;42:1337-48.

52. Brandt S, KwokT, Hartig R, König W, Backert S. NF-kappaB activation and potentiation of proinflammatory responses by the Helicobacter pylori CagA protein. Proc Natl Acad Sci USA. 2005;102:9300-5.

53. Backert S, Schwarz T, Miehlke S, Kirsch C, Sommer C, KwokT, et al. Functional analysis of the cag pathogenicity island in Helicobacter pylori isolates from patients with gastritis, peptic ulcer, and gastric cancer. Infect Immun. 2004;72:1043-56.

54. Zhang XS, Tegtmeyer N, Traube L, Jindal S, Perez-Perez G, Sticht H, Backert $\mathrm{S}$, Blaser MJ. A specific A/T polymorphism in Western tyrosine phosphorylation B-motifs regulates Helicobacter pylori CagA epithelial cell interactions. PLoS Pathog. 2015;11:e1004621. 
55. KwokT, Backert S, Schwarz H, Berger J, Meyer TF. Specific entry of Helicobacter pylori into cultured gastric epithelial cells via a zipper-like mechanism. Infect Immun. 2002;70:2108-20.

56. Selbach M, Moese S, Backert S, Jungblut PR, Meyer TF. The Helicobacter pylori CagA protein induces tyrosine dephosphorylation of ezrin. Proteomics. 2004:4:2961-8.

57. Moese S, Selbach M, Zimny-Arndt U, Jungblut PR, Meyer TF, Backert S. Identification of a tyrosine-phosphorylated $35 \mathrm{kDa}$ carboxy-terminal fragment (p35CagA) of the Helicobacter pylori CagA protein in phagocytic cells: processing or breakage? Proteomics. 2001;1:618-29.

58. Tegtmeyer N, Wittelsberger R, Hartig R, Wessler S, Martinez-Quiles N, Backert S. Serine phosphorylation of cortactin controls focal adhesion kinase activity and cell scattering induced by Helicobacter pylori. Cell Host Microbe. 2011;9:520-31.

59. Moese S, Selbach M, KwokT, Brinkmann V, König W, Meyer TF, Backert S. Helicobacter pylori induces AGS cell motility and elongation via independent signaling pathways. Infect Immun. 2004;72:3646-9.

\section{Publisher's Note}

Springer Nature remains neutral with regard to jurisdictional claims in published maps and institutional affiliations.
Ready to submit your research? Choose BMC and benefit from:

- fast, convenient online submission

- thorough peer review by experienced researchers in your field

- rapid publication on acceptance

- support for research data, including large and complex data types

- gold Open Access which fosters wider collaboration and increased citations

- maximum visibility for your research: over 100M website views per year

At BMC, research is always in progress.

Learn more biomedcentral.com/submissions 